\title{
On the Sustainability of Technology Licensing Under Asymmetric Information Game
}

\author{
Chien-Shu Tsai ${ }^{1}$, Ting-Chung Tsai ${ }^{2, *}$, Po-Sheng Ko ${ }^{3, *}$, Chien-Hui Lee ${ }^{2, *}$, Jen-Yao Lee ${ }^{2}$ (I) and \\ Yu-Lin Wang ${ }^{4}$ \\ 1 Department of Tourism Management, Kao Yuan University, Kaohsiung 82151, Taiwan; t80018@cc.kyu.edu.tw \\ 2 Department of International Business, National Kaohsiung University of Science and Technology, \\ Kaohsiung 82444, Taiwan; itjylee@kuas.edu.tw \\ 3 Department of Public Finance and Taxation, National Kaohsiung University of Science and Technology, \\ Kaohsiung 82444, Taiwan \\ 4 Department of Economics, National Chung Cheng University, Minxiong Township, Chiayi County 62102, \\ Taiwan; ecdylw@ccu.edu.tw \\ * Correspondence: caidinzhon@gmail.com (T.-C.T.); psko@nkust.edu.tw (P.-S.K.); \\ chlee@nkust.edu.tw (C.-H.L.)
}

Received: 5 November 2019; Accepted: 2 December 2019; Published: 6 December 2019

\begin{abstract}
Past research indicates that a licensor tends to adopt the fixed fee, in order to obtain higher profit rather than secure royalty when he participates in zero production in the market. This study instead finds that the patentee's optimum strategy may vary. In addition to the fixed-fee strategy, royalty or mixed licensing, or fixed fee plus royalty may be potential choices for the patentee as well which is depend on the market scale, incidence of market scale, and magnitude of cost-saving. The patentee may choose to only authorize a type of high market size based on self-interested motives. The technology licensing market is not sustainable.
\end{abstract}

Keywords: technology licensing; asymmetric information; patent

\section{Introduction}

A patent serves two purposes. The first is to provide an incentive for innovation by conferring an exclusive property right to the inventor of a new product or method of production. The second purpose served by a patent is to eliminate the need for secrecy and to bring new knowledge into the public domain [1]. As we know, the sustainability of technology (patent) licensing is related to industrial development and economic growth.

Information will frequently have an economic value, in the sense that anyone possessing the information can make greater profits than would otherwise be the case. An entrepreneur will automatically acquire the knowledge of demand and production conditions in his field, which is available to others only with special effort [2]. In the asymmetric information game, there is a "principal" who would like to condition her actions on some information that is privately known by the other players, called "agents" [3]. In the literature, the patentee can authorize a patent to the licensee through unit-royalty licensing and fixed-fee licensing [4-6].

In an asymmetric information licensing game, the "individual-rationality" or "participation" place constraints where the agents must be willing to participate in the principal's mechanism. In addition, the "implementable" or "incentive-compatible" conditions determine conditions where the agents have to choose the contract to reveal their true type. According to the game of mechanism design, in the case of the licensee (agent) having private information of demand condition, the innovator (principal) can use a fee-royalty schedule to screen the type of the licensee, if the Spence-Mirrlees condition is 
satisfied. In general, the patentee can use mixed contracts to screen firms that will make trading in the technology market permanent; however, the problem of information asymmetry might hinder the licensing behavior of the technology market. Especially, based on the motive of the patentee's expected revenue maximization, it may be that the technology licensing is not realized.

In this paper, we construct a technology-licensing model with asymmetric information to discuss the licensing strategies of the patentee. Firstly, we show that the reveal mechanisms exist. Secondly, the unit royalty licensing, fixed-fee licensing, and mixed licensing might coexist due to the market demand information being incomplete. Finally, the optimal licensing scheme of the patent is determined by the market scale, incidence of market scale, and magnitude of cost savings, which influence the expected revenue of the patentee.

The rest of this paper is organized as follows: Section 2 is the literature review. In Section 3, we explore the fundamental model of the technology licensing. The patentee's licensing strategy is discussed in Section 4 in the presence of asymmetric information, while Section 5 provides conclusions and suggestions.

\section{Literature Review}

The literature about the patentee's technology licensing can be divided into two categories in terms of whether said patentee is in the production activity. One is that the patentee participates in zero production activity. For example, under the assumptions of completely competitive and monopoly markets, Arrow [2] studies how a patentee licenses the technology by royalty. Kamien and Schwartz [7], extending Arrow's model, explore how the patentee licenses the technology in the oligopoly market. Kamien and Tauman [1], assuming a completely competitive market, compare the situation in royalties with that in fixed fees. Gallini and Winter [4] discuss the issue about how the patentee conducts the R\&D and licenses the technology with royalty. Katz and Shapiro [5,6] instead investigate the patentee's R\&D, alliance strategy, and the technology licensing with the assumption of a fixed fee. Kamien and Tauman [8] further explore how a patentee, when there are $n$ homogeneous firms in the Cournot competition, utilizes the licensing method—royalty, fixed fee or both—to achieve maximum profit. Muto [9] suggests the optimal licensing strategy for the patentee facing two heterogeneous oligopolists in the Bertrand competition (price competition), and his study results in royalty as the best solution. Lee and Huang [10], exploiting the vertical differentiation model, discuss the foreign patentee's best licensing choices-fixed fee, royalty, or its combination, and the domestic monopolist's decision regarding the product quality and price. Poddar and Sinha [11] study optimal patent licensing under the Cournot duopoly where the technology transfer takes place from an innovative firm, which is relatively inefficient in terms of cost of production, to its cost-efficient rival. They find, under non-drastic innovation, the two-part tariff is optimal when the cost difference between the firms is moderate. Kabiraj [12] shows that a tariff can influence the optimal licensing strategy of the foreign firm and a high tariff will induce fee licensing and a low tariff will result in a royalty licensing. Kim et al. [13] investigate the fixed-fee licensing contract in a mixed duopoly where public and private firms may purchase eco-technology from a foreign innovator. They show that the foreign innovator chooses either an exclusive or a non-exclusive licensing contract, depending on the cost gap between the two firms, the environmental damage caused by pollutants, and whether a public firm is privatized or not. Ad valorem royalty licensing is implemented when the licensor (i.e., patent-holding firm) obtains ownership shares in the licensee as payment once the new technology is transferred. Zhang et al. [14] investigated pricing and technology-licensing decisions in a two-echelon supply chain with one upstream firm that provides a key input to two downstream firms. They assumed that one of the downstream firms owns a licensable innovation that exhibits network effects and that the other can either accept the license from the innovator or develop a substitutable innovation. They found that royalty licensing is optimal with low network effects. Xu and Tan [15] focused on a differential game model of transboundary pollution between two asymmetric regions, one of which possesses advanced abatement technology that can reduce the abatement cost and licenses this technology to the other 
region by royalty or fixed-fee licensing. They characterized the equilibrium decisions in the regions and find that fixed-fee licensing is superior to royalty licensing from the viewpoint of both regions. In the above literature on patentee licensing, it is assumed that the patentee is isolated from any production activities; that is, the patentee only specializes in licensing and decides whether to authorize the firms to produce or not. In other words, the prior literature focuses on the patentee's behavior, with some emphasis on the royalty benefit, but the fixed-fee approach is usually a better choice in the end.

Distinct from the literature above, some researchers assume that the patentee can be both market participant and licensor. Wang [16], assuming the technology advantageous firm is a market participant and a licensor, attempts to search for this firm's optimal way of licensing and production activity in the homogeneous oligopolistic Cournot competition. His research finds that when the technology advantage is relatively trivial, the royalty to the patentee is a better way of licensing than the fixed-fee approach. However, when the patentee's technology advantage is superior enough to drive the rival out of the market, he will license none of his technology. In a heterogeneous oligopolistic Cournot competition, Wang [17] suggests that the foreign firm with technology advantage will determine its licensing strategy to the extent of commodity substitutability. The foreign firm is inclined to choose royalty if the substitutability is relatively large, but prefers the fixed-fee approach once the substitutability is relatively insignificant. Chen et al. [18] develops a mixed oligopoly model with one public firm and two private firms to explore the licensing strategy considered by the innovative private firm. They find the public firm may or may not accept the technology licensing offer from the private firm; if the public firm accepts the licensing, all of the three different types of licensing contracts (royalty, fixed-fee and two-part tariff) can all be optimal licensing contracts to the same degree.

However, for these two categories of the literature mentioned above, the licensing choice for a patentee is limited to either royalty or the fixed-fee policy. The mixed licensing, fixed fee plus royalty, is yet to be discussed among the potential licensing choices. In the US, in their study of US enterprise licensing contracts, Taylor and Silberston [19] found that $50 \%$ of patentees practiced licensing through royalty, $10 \%$ utilized the fixed fee, while the remaining $40 \%$ exploited two-part pricing or a more complicated pricing policy. Rostoker's research [20] reveals that with respect to the technology licensing strategies, $39 \%$ of the patentees exploit the royalty, and $13 \%$ of them employ it with the fixed fee. Surprisingly, $46 \%$ of them select the mixed strategy-royalty plus fixed fee. Additionally, technology licensing has many other options besides unit royalty and fixed-fee. For example: technology shares, auctions, bargaining, cross-licensing, ad valorem royalties and up-front payment, etc. Related discussion can refer to Katz and Shapiro [6], Stamatopoulos and Tauman [21], Kishimoto et al. [22], Miao [23], Heywood et al. [24], Jeon and Lefouili [25], and Lee et al. [26]. However, unit royalty and fixed-fee licensing remain the most important licensing tools in the theory and practice.

Past literature shows that when the patentee participates in zero production, the revenue of the fixed-fee strategy is higher than that of the royalty. However, empirical studies have shown that unit royalties, fixed-fee, and mixed royalties coexist in the market $[19,20]$. This study focuses on the varied choices between unit royalty and fixed fee. We consider that the patentee's optimal strategy can actually vary due to the market information being incomplete in the licensing game. (There are many factors affecting technology licensing, such as market factors, technical factors, financial factors and environmental factors. According to Lee et al. [27], they found that market factors were considered to be the most important determinant regardless of national research institutions, companies and national institutions. In order to make this study more focused on theoretical discussion, we still use market factors as the discussion object.)

Our research aims to explore several issues. Is there a screening contract for technology licensing under the asymmetrical information? Is the optimal authorization contract unique? What are the conditions for the screening contract as an optimal contract? May technology licensing be sustainable?

With respect to transnational production and investment, it is of paramount importance to keep up with any information relevant to market scale; however, the information search cost may be extraordinarily high. Asymmetric information, thus, can exert a significant impact on one firm's 
decision. Beggs [28] seeks to explain the use of royalty payments rather than fixed fees in the licensing of patents by the presence of asymmetric information. The licensee is assumed to know the value of the patent and makes a single offer of a contract to the licensor. It is shown that there is a unique equilibrium satisfying Cho and Kreps' intuitive criterion, where qualitative properties of the equilibrium contract are derived by considering a continuum of types. Sen [29] suggests that when the authorized firm owns private information regarding cost types, the patentee may induce this firm to reveal its type through choosing from the menus of contracts. A standard screening model exists in his study since there is a reverse choice in the market; however, his research neglects whether the patentee is willing to choose even though he has the menus of contracts. Fan [30] reconsiders the inside patent holders' optimal licensing problem of non-drastic and (super-) drastic innovations under incomplete information, taking into account restrictions concerning royalty rates and the use of exclusive licenses implied by antitrust rules.

The main contributions of this study are as follows. Firstly, we show that the equilibrium is not unique, and the pooling equilibrium and the separating equilibrium may be adopted, which is dependent on the difference of market scale, incidence of market scale, and magnitude of cost saving. The licensing strategies of fixed-fee, unit royalty, and mixed could coexist. Secondly, we found that if the difference of revenue between two types of market demand is sufficiently large, the patentee will only authorize the firm with a large market scale, the screening mechanism might not be used under asymmetric information, and the technology licensing may not be sustainable.

In the next sections, we establish a technology licensing game with perfect information and asymmetric information to explore the licensing strategies choice of the patentee. Using a two-stage dynamic game of licensing under perfect information, the concept of Subgame Perfect Nash Equilibrium is applied. The concept of mechanism design and perfect Bayesian Nash equilibrium are applied in the asymmetric information licensing game [31,32].

\section{A Model of Technology Licensing}

We first establish four models within the framework of respective licensing strategies in the presence of perfect information, and these models can be used to study the licensing strategy choices under asymmetric information. They are reported in the following sections labeled 3.1 to 3.4.

\subsection{Model without Technology Licensing (with $n$ Being the Relevant Variable)}

Following Kamien and Tauman [8], we assume that the inverse demand function of the domestic market is $p=a-q$, where $a$ denotes the parameter of the market scale, $p$ stands for price, and $q$ represents the quantity demanded. We also suggest that the domestic firm is a monopolist, and his marginal cost before the authorization is $c$, where the fixed cost is zero, and $0<c<a$. With this assumption, we can derive the firm's profit function, $\pi_{n}=(p-c) q_{n}$ from which the optimal production and profit of this firm are

$$
\begin{aligned}
q_{n}^{*} & =\frac{1}{2}(a-c), \\
\pi_{n}^{*} & =\frac{1}{4}(a-c)^{2} .
\end{aligned}
$$

\subsection{Model with the Fixed Fee (with $f$ Being the Relevant Variables)}

We assume that the patentee authorizes through the fixed fee $(F)$, and his revenue function is $R_{f}=F$. It is also assumed that the technology invention owned by the patentee can save the cost by $\varepsilon$. In addition, and the domestic firm, after being authorized the technology, can reduce the marginal cost to $c-\varepsilon$, and $0<\varepsilon \leq c$. The firm's profit function, therefore, is $\pi_{f}=(p-c+\varepsilon) q_{f}-F$. We solve the maximization problems by backward induction under the premise of Subgame Perfect Nash equilibrium (SPNE). As long as the firm's profit after the authorization acquirement is no less than that 
before the authorization, the firm is expected to seek authorization; thus, we have the firm's production and profit function and the patentee's revenue:

$$
\begin{aligned}
q_{f}^{*} & =\frac{1}{2}(a+\varepsilon-c), \\
\pi_{f}^{*} & =\frac{1}{4}(a-c)^{2}, \\
R_{f}^{*}=F^{*} & =\frac{1}{4} \varepsilon(2 a+\varepsilon-2 c) .
\end{aligned}
$$

\subsection{Model with the Royalty (with $r$ Being the Relevant Variable)}

We suppose that the patentee authorizes through the royalty $(r)$ and as such the patentee's profit function is $R_{r}=r q_{r}$. Then, the firm has his profit function as $\pi_{r}=(p-c+\varepsilon-r) q_{r}$. Likewise, the royalty paid to the patentee should be less than the cost saved resulting from the licensed technology, or the firm will not seek authorization; that is, $r \leq \varepsilon$. We further break it down into the following two scenarios:

Scenario 1: When $a<\varepsilon+c$, the patentee's royalty is $r^{*}=\frac{1}{2}(a+\varepsilon-c)$, and $r^{*}<\varepsilon$.

Given this, the firm's production and profit function and the patentee's revenue function are presented in the following, respectively ( $i$ denotes an interior solution):

$$
\begin{aligned}
q_{r i}^{*} & =\frac{1}{4}(a+\varepsilon-c), \\
\pi_{r i}^{*} & =\frac{1}{16}(a+\varepsilon-c)^{2}, \\
R_{r i}^{*} & =\frac{1}{8}(a+\varepsilon-c)^{2} .
\end{aligned}
$$

Scenario 2: When $a \geq \varepsilon+c$, the patentee's royalty is $r^{*}=\varepsilon$.

Then, the firm's production and profit function and the patentee's revenue function can be shown as follows ( $c$ denotes a corner solution):

$$
\begin{aligned}
q_{r c}^{*} & =\frac{1}{2}(a-c), \\
\pi_{r c}^{*} & =\frac{1}{4}(a-c)^{2}, \\
R_{r c}^{*} & =\frac{1}{2} \varepsilon(a-c) .
\end{aligned}
$$

\subsection{Model with the Mixed Licensing (with $m$ Being the Relevant Variable)}

Now suppose that the patentee authorizes through the royalty plus the fixed fee (a mixed method); he will not decide on the monetary amount of the fixed fee until the optimal royalty is determined. In such a mixed licensing strategy, the revenue function of the patentee is $R_{m}=r q_{m}+F_{m}$, while the profit function of the authorized firm is $\pi_{m}=(p-c+\varepsilon-r) q_{m}-F_{m}$. Again, we can discuss the following two scenarios.

Scenario 1: When $a<\varepsilon+c$, what the patentee can get for the royalty is $r^{*}=\frac{1}{2}(a+\varepsilon-c)$.

The firm's production and profit function and the patentee's revenue function can be expressed as the following respectively:

$$
q_{m i}^{*}=\frac{1}{4}(a+\varepsilon-c)
$$




$$
\begin{gathered}
\pi_{m i}^{*}=\pi_{n^{\prime}}^{*} \\
R_{m i}^{*}=\frac{1}{8}(a+\varepsilon-c)^{2}+\frac{1}{16}(3 a+\varepsilon-3 c)(\varepsilon-a+c) .
\end{gathered}
$$

Scenario 2: When $a \geq \varepsilon+c$, what the patentee can get for the royalty is $r^{*}=\varepsilon$.

The firm's production and profit functions and the patentee's revenue function are shown in the following:

$$
\begin{gathered}
q_{m c}^{*}=\frac{1}{2}(a-c), \\
\pi_{m c}^{*}=\pi_{n}^{*}, \\
R_{m c}^{*}=\frac{1}{2} \varepsilon(a-c) .
\end{gathered}
$$

We can outline in the following the firm's production and profit functions and the patentee's revenue function in the case when the patentee adopts different licensing strategies:

Lemma 1. When $a<\varepsilon+c$, we have $q_{f}^{*}>q_{m i}^{*}=q_{r i}^{*}>q_{n}^{*}, \pi_{r i}^{*}>\pi_{f}^{*}=\pi_{m i}^{*}=\pi_{n}^{*}$, and $R_{f}^{*}>R_{m i}^{*}>R_{r i}^{*}$; when $a \geq \varepsilon+c$, we have $q_{f}^{*}>q_{m c}^{*}=q_{r c}^{*}=q_{n}^{*}, \pi_{r c}^{*}=\pi_{f}^{*}=\pi_{m c}^{*}=\pi_{n}^{*}$, and $R_{f}^{*}>R_{m c}^{*}=R_{r c}^{*}$.

Given the above comparisons, we can now state the following proposition:

Proposition 1. When the patentee is an outsider, in the presence of perfect information, the revenue of the fixed-fee strategy is superior to that of the royalty, better than that of the mixed licensing strategy. In other words, the patentee has a tendency to adopt the fixed fee strategy as his licensing policy.

Proposition 1 is consistent with Kamien and Tauman [8], where they found that licensing by means of a fixed fee is superior to licensing by means of a royalty for the patent holder. Furthermore, we find that a mixed licensing strategy is not necessary under perfect information. The economic reasons are as the following. On the premise that the patentee participates in zero production, it is interesting to gauge to the profit change of an authorized domestic firm before and after the royalty payment. First, with the unchanged production and its lower cost, the domestic firm will experience profit increase due to the cost saving, and as such it is called cost-saving effect. On the contrary, after the technology licensing, if the domestic firm's marginal cost is reduced and its production increased, the profit is expected to increase due to the production increase, and hence is called production effect. Suppose that the profit after the licensing is no less than that before licensing, the domestic firm desires to seek authorization; as a result, the patentee can license through the fixed fee, enabling the domestic firm to achieve maximum production effect. Given an elastic demand, it would like to obtain the maximum fixed fee. The production effect under the royalty is zero, and the corresponding royalty the patentee receives is definitely the worst of all methods.

\section{Technology Licensing under Asymmetric Information}

The discussion in the previous section, like that in other literature, concludes that the patentee, in the presence of perfect information, tends to utilize the fixed fee as his or her licensing policy. The result, however, fails to echo the proposition mentioned in the introduction: the patentee's best licensing choice may actually vary. This section, discussed from the point of asymmetric information regarding market scale, elucidates why the patentee's best licensing may vary.

\subsection{The Model with Asymmetric Information}

A foreign patentee, usually, may not fully understand the information about the domestic market scale, which may only be observed by the domestic firms and treated as private information. That is, there is asymmetric information about the domestic market scale between the foreign patentee and the 
domestic firm. To simplify the analysis, we assume that the domestic market scale may be large or small. In detail, if the domestic market scale with the incidence of $P\left(a_{h}\right)=\theta$, is large (namely type $h)$, the vertical intercept of its inverse demand function will be $a_{h}$. If the domestic market scale, with the incidence of $P\left(a_{l}\right)=1-\theta$, is small (namely type $l$ ), the vertical intercept of its inverse demand function will be $a_{l}$, given $a_{h}>a_{l}$ and $0<\theta<1$. Meanwhile, it is well assumed that the type of the domestic market scale consists of private information to domestic firms, and the incidence rate is common knowledge.

In light of the elucidation above, we next exploit the theorem of perfect Bayesian Nash equilibrium to solve the model [32]. The decision sequence is explained hereinafter. First, the foreign patentee will, considering the domestic firms' production behavior, determine his optimal licensing choice combination in order to maximize his expected target values. Secondly, the domestic firm, given the licensing choice combination presented by the foreign patentee, is expected to accept this combination and choose the optimal production in order to maximize his profit. The concept of mechanism design and perfect Bayesian Nash equilibrium are applied in the asymmetric information licensing game [31,32].

In the determination of the licensing choice combination, the patentee can present the same, and the solution is known as pooling equilibrium in the literature; however, he can also present dual sets of licensing choice combination, resulting in so-called separating equilibrium in the literature [32].

In the presence of asymmetric information, the patentee's objective is:

$$
\begin{aligned}
& \text { Max. } E R \equiv \theta\left(r_{h} q_{h}+F_{h}\right)+(1-\theta)\left(r_{l} q_{l}+F_{l}\right), \\
& r_{l}, r_{h} \\
& F_{l}, F_{h}
\end{aligned}
$$

where $r_{i}$ and $F_{i}$ respectively denote the royalty and fixed fee paid by the $i$ type firm when the patentee licenses the $i$ type firm. Given the royalty combination presented by the patentee, if $r_{l}^{*}=r_{h}^{*}=r_{p}^{*}$ and $F_{l}^{*}=F_{h}^{*}=F_{p}^{*}$, we call $\left(r_{p}^{*}, F_{p}^{*}\right)$ the pooling equilibrium. Likewise, if $r_{l}^{*} \neq r_{h}^{*}$ and $F_{l}^{*} \neq F_{h^{\prime}}^{*}$ we call $\left(r_{l}^{*}, F_{l}^{*}\right)$ and $\left(r_{h}^{*}, F_{h}^{*}\right)$ the separating equilibrium.

Then, the firm's individual rationality (or IR) to desire the authorization under the large or small market is shown in the following parts:

$$
\begin{gathered}
\frac{1}{4}\left(a_{h}-c+\varepsilon-r_{h}\right)^{2}-F_{h} \geq \frac{1}{4}\left(a_{h}-c\right)^{2}, \\
\frac{1}{4}\left(a_{l}-c+\varepsilon-r_{l}\right)^{2}-F_{l} \geq \frac{1}{4}\left(a_{l}-c\right)^{2},
\end{gathered}
$$

In addition to the IR constraints in Equations (19) and (20), the separating equilibrium should also meet the following two incentive compatibility constraints (or IC).

$$
\begin{aligned}
& \frac{1}{4}\left(a_{h}-c+\varepsilon-r_{h}\right)^{2}-F_{h} \geq \frac{1}{4}\left(a_{h}-c+\varepsilon-r_{l}\right)^{2}-F_{l^{\prime}} \\
& \frac{1}{4}\left(a_{l}-c+\varepsilon-r_{l}\right)^{2}-F_{l} \geq \frac{1}{4}\left(a_{l}-c+\varepsilon-r_{h}\right)^{2}-F_{h^{\prime}}
\end{aligned}
$$

Equations (21) and (22) represent that when the $h$ type firm chooses the contract for the type, $\mathrm{h}$ will always be worth more than choosing the contract for the $l$ type and vice versa. In other words, if these two mixed licensing choice combinations, $\left(r_{l}^{*}, F_{l}^{*}\right)$ and $\left(r_{h}^{*}, F_{h}^{*}\right)$, meet the incentive compatibility constraints of Equations (21) and (22), domestic firms will surely choose the licensing choice, which is consistent with what is observed in the actual market. This is known as the sorting (or Spence-Mirrless) condition. Both types of the firms will always choose the contract of their true types. 


\subsection{Pooling Equilibrium}

First, we focus on the derivation of pooling equilibrium $\left(r_{p}^{*}, F_{p}^{*}\right)$ of the patentee. As mentioned above, under the pooling equilibrium, the patentee will set a unitary set of royalty and fixed fee regardless of the market scale, large or small. We will further explore how the patentee fixes $r_{p}^{*}$ and $F_{p}^{*}$, and the discussion will be divided according to two scenarios: (1) regardless of the domestic market scale, large or small, domestic firms will prefer the authorization; (2) only when the domestic market is large, will the domestic firms seek the authorization.

In scenario (1), we envision that the patentee hopes that domestic firms, whatever size the market scale, will demand the authorization. From the conditions Equations (19) and (20), we find that as long as Equation (20) is valid, the condition of Equation (19) will automatically be satisfied; that is, once the firm under the small market scale is willing to obtain the authorization, the firm with the large market scale will also follow suit. On the other hand, in scenario (2), the patentee only cares about whether the firms under large market scale want the authorization, but ignores the demands of other firms with small market scales. That is, the fact that the firms with large market scale profit less than that before the authorization implies Equation (19) is valid.

In what follows, we present the following two pooling equilibriums (The pooling equilibrium under the mixed licensing, a manipulated choice, is not discussed in this research) under scenario (1): The first pooling equilibrium (denoted by $p 1$ ) implies that given the fixed fee by the patentee, the domestic firms under large or small market scale will all seek authorization. We obtain:

$$
\begin{gathered}
F_{p 1}^{*}=\frac{1}{4} \varepsilon\left(2 a_{l}+\varepsilon-2 c\right), \\
r_{p 1}^{*}=0, \\
P\left(c_{h} \mid F_{p 1}^{*}, r_{p 1}^{*}\right)=\theta, \\
P\left(c_{l} \mid F_{p 1}^{*}, r_{p 1}^{*}\right)=(1-\theta), \\
E R_{p 1}^{*}=\theta\left[\frac{1}{4} \varepsilon\left(2 a_{l}+\varepsilon-2 c\right)\right]+(1-\theta)\left[\frac{1}{4} \varepsilon\left(2 a_{l}+\varepsilon-2 c\right)\right] \\
=\frac{1}{4} \varepsilon\left(2 a_{l}+\varepsilon-2 c\right)=\frac{1}{2} \varepsilon\left(a_{l}-c\right)+\frac{1}{4} \varepsilon^{2}
\end{gathered}
$$

We found that the expected royalty revenue of the patentee is an increasing function of cost saving effect $(\varepsilon)$. Additionally, the firms under these two types of market will also demand the authorization, so the expected value will not be affected by incidence rate of the large market scale $(\theta)$.

The second pooling equilibrium (denoted by $p 2$ ) suggests that when the patentee licenses through the royalty, both firms with small or large market scales would prefer the authorization. We obtain:

$$
\begin{gathered}
F_{p 2}^{*}=0, \\
r_{p 2}^{*}=\varepsilon \\
P\left(c_{h} \mid F_{p 2}^{*}, r_{p 2}^{*}\right)=\theta, \\
P\left(c_{l} \mid F_{p 2}^{*}, r_{p 2}^{*}\right)=(1-\theta), \\
E R_{p 2}^{*}=\theta\left[\frac{1}{2} \varepsilon\left(a_{h}-c\right)\right]+(1-\theta)\left[\frac{1}{2} \varepsilon\left(a_{l}-c\right)\right] \\
=\frac{1}{2} \varepsilon\left[\theta a_{h}+(1-\theta) a_{l}-c\right]=\frac{1}{2} \varepsilon\left(a_{l}-c\right)+\frac{1}{2} \varepsilon \theta\left(a_{h}-a_{l}\right)
\end{gathered}
$$

We observe that the expected royalty revenue is an increasing function of the cost-saving effect $(\varepsilon)$ and the incidence of large market scale $(\theta)$.

Further, we can derive the pooling equilibrium under scenario (2) as shown below. 
The third pooling equilibrium (represented by $p 3$ ) indicates that when the patentee licenses through the fixed fee, only the firm with large market scale will desire the authorization. We obtain:

$$
\begin{gathered}
F_{p 3}^{*}=\frac{1}{4} \varepsilon\left(2 a_{h}+\varepsilon-2 c\right), \\
r_{p 3}^{*}=0, \\
P\left(c_{h} \mid F_{p 3}, r_{p 3}\right)=\theta, \\
P\left(c_{l} \mid F_{p 3}, r_{p 3}\right)=(1-\theta), \\
E R_{p 3}^{*}=\theta\left[\frac{1}{4} \varepsilon\left(2 a_{h}+\varepsilon-2 c\right)\right]=\theta\left[\frac{1}{2} \varepsilon\left(a_{h}-c\right)+\frac{1}{4} \varepsilon^{2}\right] .
\end{gathered}
$$

Likewise, we now observe that the expected royalty revenue is an increasing function of the cost saving effect $(\varepsilon)$ and the incidence of large market scale $(\theta)$.

By comparing the patentee's different expected revenues under these three different pooling equilibriums, we set forth the following lemma:

\section{Lemma 2.}

(i) $E R_{p 1}^{*}-E R_{p 2}^{*}>0$, when $\theta<\theta_{1} \equiv \frac{\varepsilon}{2\left(a_{h}-a_{l}\right)}$;

(ii) $E R_{p 1}^{*}-E R_{p 3}^{*}>0$, when $\theta<\theta_{2} \equiv \frac{2\left(a_{l}-c\right)+\varepsilon}{2\left(a_{h}-c\right)+\varepsilon}$;

(iii) $E R_{p 2}^{*}-E R_{p 3}^{*}>0$, when $\theta<\theta_{3} \equiv \frac{2\left(a_{l}-c\right)}{2\left(a_{l}-c\right)+\varepsilon}$.

Proof. See Appendix A.

Lemma 3. If $\varepsilon<2\left(a_{h}-a_{l}\right)$, then $\theta_{3}>\theta_{2}>\theta_{1}$.

Proof. See Appendix B.

Moreover, by invoking lemma 2, we can have definite numerical comparisons among these pooling equilibriums given different incidence rates. In this light, we can also state the following proposition.

Proposition 2. Under asymmetric information, the patentee will choose the optimal licensing choice of pooling equilibrium hinging on the combination of the following three parameters: the market scale difference $\left(\Delta a=a_{h}-a_{l}\right)$, incidence of large market scale $(\theta)$, and the marginal cost $(c)$. In particular, (1) given $\varepsilon \geq 2 \Delta a$, if $\theta \geq \theta_{2}, p 3$ is the best policy; if $\theta<\theta_{2}, p 1$ is the best policy; (2) given $\varepsilon<2 \Delta a$, if $\theta \geq \theta_{3}$, $p 3$ is the best policy; if $\theta_{3}>\theta \geq \theta_{1}, p 2$ is the best policy; if $\theta<\theta_{1}, p 1$ is the best policy.

Proof. See Appendix C.

On the determination of the pooling equilibrium, the patentee will decide according to the magnitude of $\theta$. If the incidence rate is high, the patentee, assuming that the market is of a large scale, is expected to fix a fee, which only the firm under large market scale can afford. Likewise, if the incidence rate is low, the patentee will fix a fee that is acceptable by both types of firms. However, when the market has a high probability of high scale, only when the manufacturer faces a high market size, technology transfer can be achieved. The reasons are as follows. When the magnitude of cost-reducing innovation is large, the value of the patent is high, and the expected loss of the patentee who chooses to license the firm with low market scale is relatively high. The patentee will choose a contract to license only the firm with high market scale. In the same reason, the market demand difference is large, the 
expected loss of the patentee who chooses to license the firm with low market scale is relatively high. The patentee will choose to license the firm with high market scale. However, if the real market size of this manufacturer is low, technical authorization will not be obtained, market production will fall into low efficiency, and technology licensing will not be sustainable.

\subsection{Separating Equilibrium}

We now consider the separating equilibrium; that is, how the patentee uses price discrimination through fixing two sets of mixed licensing, to detect the actual market scale in which the firms exist. Here, we can observe that when under two different market scales, large or small, the firms' iso-profit curves satisfy single crossing condition on the plane of $(r, F)$. Therefore, the patentee, given the conditions on other parameters, can certainly design one optimal separating equilibrium. The incentive design of the authorization contract is aimed to enable the firm, subject to the condition of individual rationality and incentive compatibility, to choose the most suitable contract in order to maximize his or her own profit. In general, if the patentee assumes that the market is a small one, he or she will fix the optimal royalty combination $\left(r_{l}^{*}, F_{l}^{*}\right)$ accordingly, which is to be welcomed by firms with large market scale.

Thus, to solve this model given the market scale is small, the equation of the individual rationality is assumed to be binding, and hence we can derive the royalty combination. Next, using the combination and the condition of incentive compatibility or (3.4), we can figure out the royalty combination for the market large scale. As in the foregoing discussion, when $a_{l}<\varepsilon+c$ or $a_{l} \geq \varepsilon+c$ respectively, the best separating equilibrium that satisfies IR and IC and the patentee's optimal target value are respectively presented in the following:

Separating equilibrium 1 (denoted by $s 1$ ): the separating equilibrium given $a_{l}<\varepsilon+c$, we obtain:

$$
\begin{gathered}
F_{h 1}^{*}=\frac{1}{4}\left[\left(c+\varepsilon-a_{l}\right) a_{l}+a_{h}\left(a_{l}+\varepsilon-c\right)-\varepsilon(2 c-\varepsilon)\right], \\
r_{h 1}^{*}=0, \\
F_{l 1}^{*}=\frac{1}{16}\left(3 a_{l}+\varepsilon-3 c\right)\left(\varepsilon-a_{l}+c\right), \\
r_{l 1}^{*}=\frac{1}{2}\left(a_{l}+\varepsilon-c\right)<\varepsilon, \\
P\left(a_{h} \mid F_{h 1}^{*}, r_{h 1}^{*}\right)=1, \\
P\left(a_{l} \mid F_{l 1}^{*}, r_{l 1}^{*}\right)=1, \\
E R_{s 1}^{*}=\frac{1}{4} \theta\left[\left(c+\varepsilon-a_{l}\right) a_{l}+a_{h}\left(a_{l}+\varepsilon-c\right)-\varepsilon(2 c-\varepsilon)\right] \\
+\frac{1}{16}(1-\theta)\left[\left(3 a_{l}+\varepsilon-3 c\right)\left(\varepsilon-a_{l}+c\right)+\frac{1}{8}\left(a_{l}+\varepsilon-c\right)^{2}\right]
\end{gathered}
$$

Separating equilibrium 2 (denoted by $s 2$ ): the separating equilibrium given $a_{l} \geq \varepsilon+c$, we obtain:

$$
\begin{gathered}
F_{h 2}^{*}=\frac{1}{4} \varepsilon\left(2 a_{h}+\varepsilon-2 c\right), \\
r_{h 2}^{*}=0, \\
F_{l 2}^{*}=0, \\
r_{l 2}^{*}=\varepsilon, \\
P\left(a_{h} \mid F_{h 2}^{*}, r_{h 2}^{*}\right)=1, \\
P\left(a_{l} \mid F_{l 2}^{*}, r_{l 2}^{*}\right)=1,
\end{gathered}
$$




$$
E R_{s 2}^{*}=\frac{1}{4} \theta \varepsilon\left(2 a_{h}+\varepsilon-2 c\right)+\frac{1}{2} \varepsilon(1-\theta)\left(a_{l}-c\right)=\frac{1}{4} \varepsilon\left[2 \theta\left(a_{h}-a_{l}\right)+2\left(a_{l}-c\right)+\varepsilon \theta\right] .
$$

Proposition 3 can be readily derived given the two separate equilibriums $s 1$ and $s 2$.

Proposition 3. In the presence of asymmetric information, when the market scale is small $\left(a_{l}<\varepsilon+c\right)$, the separating equilibrium is $s 1$; while when the market scale is large $\left(a_{l} \geq \varepsilon+c\right)$, the separating equilibrium is $s 2$.

We have found that the mixed licensing will be utilized when the market scale is relatively small. When the market scale is relatively small, the patentee will fix the optimal royalty for the firms with small market scale. When the royalty is less than the cost savings resulting from this authorized technology, it will create a production effect. Thus, the patentee still can receive a sum of fixed fee. As to firms with the large scale, what the patentee can do, given the authorization contract of small market scale, is try to increase the fixed fee as much as possible without disturbing the condition of incentive compatibility in order to exploit the firms' profit.

On the contrary, when the market scale is relatively large, the patentee can charge the royalty for the firms according to the extent of cost savings due to the authorized technology, but charges no extra fixed fee for there's no production effect emanating from this authorization. As for firms with the large-scale market, the patentee can raise the fixed fee to the level under perfect information. In other words, as long as the policy s 2 adopted by the patentee is concerned, patentee licenses the large-scale and small-scale firms through different strategies, fixed fee royalty and unit royalty respectively.

On the other hand, given the licensing combination of separating equilibrium, the firm will choose the authorization contract that fits its needs. In the meanwhile, the patentee will change his belief in the knowledge about the firm's types when he chooses the large market scale contract. The conditional probability of the firm is $P\left(a_{h} \mid F_{h 2}^{*}, r_{h 2}^{*}\right)=1$. When the screening contract is designed, it will ensure that the firms can obtain technical authorization regardless of the size of the market.

\subsection{The Patentee's Choice between the Pooling Equilibrium and Separating Equilibrium}

From the discussion in Section 4.3, we have found that the patentee can induce the firm to reveal its characteristics by a well-designed incentive contract. However, the patentee will not have the incentive to fix the contract leading to the separating equilibrium unless the profit of the separating equilibrium is higher than that of the pooling equilibrium. We will further explore this issue in the following.

By utilizing the result in Proposition 2 and Proposition 3, we can compare the different optimal authorizations under different market scales, given the incidence of large market scale. First, we offer the explanation on the patentee's best choice when the market scale is small. (To simplify the analysis, we only discuss the best licensing choice when $\varepsilon \geq 2 \Delta a$.)

Proposition 4. Given that the low market scale is relatively small $\left(a_{l}<\varepsilon+c\right)$, where $\varepsilon \geq 2 \Delta a$ and $a_{l}-c>\frac{7}{9} \varepsilon$, when $\theta \leq \theta_{4}$, the patentee's best choice is $p 1$ : a pooling equilibrium. Conversely, when $\theta_{4}<\theta<\theta_{5}$, the patentee's best choice is s1: a separating equilibrium. However, if $\theta \geq \theta_{5}$, the best choice of the patentee is p3: a pooling equilibrium. Of this proposition, $\theta_{4}$ and $\theta_{5}$ are restricted to be $\theta_{4} \equiv \frac{23\left(a_{l}+\varepsilon-c\right)}{23\left(a_{l}+\varepsilon-c\right)+32\left(a_{h}-a_{l}\right)}$, $\theta_{5} \equiv \frac{23 c^{2}+18 c \varepsilon-9 \varepsilon^{2}+a_{l}\left(23 a_{l}-18 \varepsilon-46 c\right)}{23 c^{2}+18 c \varepsilon-9 \varepsilon^{2}+a_{l}\left(23 a_{l}-18 \varepsilon-46 c\right)+32\left(a_{h}-a_{l}\right)\left(a_{l}+\varepsilon-c\right)}$.

Proof. See Appendix D.

Proposition 4 states that when the innovation is drastic and the low market scale is relatively small, the third pooling equilibrium ( $p 3$ ) will be adopted. Our results are different with Kamien and Tauman [9]. The fixed fee licensing is not always the optimal licensing strategy under asymmetric information. The reasons are provided as proposition 2 . If the low market scale is relatively small with high incidence of high demand and drastic innovation, the expected profit of the $p 3$ of the patentee 
is high, and $p 3$ will be implemented. At this time, if the actual market size is low, the technical authorization will not be obtained. That is to say, the patentee may choose to only authorize a type of high market size based on self-interested motives. The technology licensing market is not sustainable. In what follows, we elucidate the patentee's best choice when the market scale is large.

Proposition 5. Given that the low market scale is relatively large $\left(a_{l} \geq \varepsilon+c\right)$, when $\theta<\theta_{6^{\prime}}$ the patentee's best choice is $p 1$ : a pooling equilibrium, while for $\theta_{6} \leq \theta$, the best choice of the patentee is s2: a separating equilibrium in which $\theta_{6} \equiv \frac{\varepsilon}{\varepsilon+2\left(a_{h}-a_{l}\right)}$.

Proof. See Appendix E.

From Proposition 4 and Proposition 5, it is clear that when the value of $\theta$ is diminutive, meaning that the incidence of small market scale is high, the patentee assuming that the authorized firms, facing a small market scale, will therefore adopt a fixed fee of the pooling equilibrium ( $p 1)$. Such a strategy is acceptable to both types of firms, large scale and small scale, in order to exploit the firms' extra profit resulting from this technology authorization. When the value of $\theta$ is very large, meaning that the incidence of large market scale is high, the patentee will adopt the fixed-fee of pooling equilibrium, $p 3$. However, when the value of $\theta$ is in-between, the patentee, facing a high uncertainty, can only screen the firms through mixed licensing and raise the royalty as much as possible.

\section{Conclusions and Suggestion}

The past literature shows that when the patentee participates in zero production, the revenue of the fixed-fee strategy is higher than that of the royalty. However, empirical studies have shown that unit royalties, fixed-fee, mixed royalties, and more complex forms of authorization coexist in the market $[19,20]$. In order to continue the advancement of the theory, this study focus on the vary choices between unit royalty and fixed fee. We consider that the patentee's optimal strategy can actually vary due to the market information is incomplete in the licensing game.

Our research aims to explore several issues. Is there a screening contract for technology licensing under the asymmetric information? Is the optimal authorization contract unique? What are the conditions for the screening contract as an optimal contract? May technology licensing be sustainable?

To explore the above issues, in this paper, a simplified model of asymmetric information is used to prove that the patentee may have different optimal choices when the authorized firm possesses private information about market scale. In other words, the revenue under the fixed-fee strategy is not necessarily the optimal equilibrium for the patentee, since the patentee may rely on the mixed licensing combination in detecting the type of a firm for higher expected revenue.

From this research, we find that when information is perfect, the best licensing policy for a patentee is the fixed-fee strategy, which is consistent with other literature. However, when the authorized firm possesses private information about the market scale, the patentee's optimal licensing policy varies depending upon some parameter values such as the market scale difference, the incidence of large market scale and the cost of the authorized firm.

Two major results are offered from our paper: (1) When the scale of a market is relatively small, and the incidence of large market scale is high, the optimal licensing policy for the patentee is that of a fixed fee, which is only accepted by the firms with large market scale. Otherwise, if the incidence of large market scale is relatively small, the patentee's optimal licensing strategy is that of a fixed fee, which is accepted both by firms with large or small market scale. If the incidence of large market scale is in between, the optimal licensing strategy will be the mixed licensing, which consists of unit royalty plus fixed fee. (2) When the scale of a market is relatively large, and the incidence of large market scale is high, the patentee is expected to adopt the mixed licensing. If the incidence of large market scale is instead relatively small, the patentee's optimal licensing strategy is that of a fixed fee, which can only be accepted by the firms with large market scale. The technology licensing market is not sustainable. 
When the authorized firm owns the private information about market scale, the patentee will adopt the separating equilibrium since screening the type of firms is costly. The patentee, therefore, fails to adopt the best strategy under perfect information but chooses both the fixed-fee and the royalty in order to exploit the profit of the authorized firms and to increase his own revenue. However, if the cost of screening the authorized firm is too high, the patentee will revert to the pooling equilibrium as his best strategy. If the real market size of this manufacturer is low, technical authorization will not be obtained, market production will fall into low efficiency, and technology licensing will not be sustainable.

The game analysis method used in this study had some limitations. First of all, this study assumes that the type of market demand is high or low. In the real economy, the market demand may distribute by other forms of distribution such as normal distribution. Secondly, this study only discusses that the licensee with private information, but the patentee's private information about the patent may also affect its authorization strategy. Third, this article assumes that there is only one potential licensee in the market, but there may be multiple vendors coexisting in the market. It is suggested that in future research, the influence of different market structures on the choice of technology licensing contracts can be further considered.

Author Contributions: Conceptualization, C.-S.T., T.-C.T. and J.-Y.L.; Funding acquisition, J.-Y.L.; Investigation, C.-S.T., C.-H.L and P.-S.K.; Methodology, C.-S.T., T.-C.T. and C.-H.L.; Supervision, Y.-L.W.; Writing-original draft, C.-S.T. and C.-H.L.; Writing—-review \& editing, P.-S.K.

Funding: This research was funded by the Taiwan Ministry of Science and Technology with grant number [NSC 97-2410-H-151 -020]. The APC was funded by National Kaohsiung University of Science and Technology, Taiwan.

Acknowledgments: We would like to thank Professor Chin-shu Huang and four anonymous referees for their useful comments and constructive suggestions.

Conflicts of Interest: The authors declare no conflict of interest.

\section{Appendix A Proof of Lemma 2}

(i) Since $E R_{p 1}^{*}-E R_{p 2}^{*}=\frac{1}{4} \varepsilon\left[\varepsilon-2 \theta a_{h}+2 \theta a_{l}\right]>0$, it follows

when $\varepsilon-2 \theta a_{h}+2 \theta a_{l}>0 \Leftrightarrow \varepsilon>2 \theta\left(a_{h}-a_{l}\right) \Leftrightarrow \theta<\frac{\varepsilon}{2\left(a_{h}-a_{l}\right)}$.

(ii) Since $E R_{p 1}^{*}-E R_{p 2}^{*}=\frac{1}{4} \varepsilon\left[-(1-\theta)(2 c-\varepsilon)-2\left(\theta a_{h}-a_{l}\right)\right]>0$, it follows

when $-(1-\theta)(2 c-\varepsilon)-2\left(\theta a_{h}-a_{l}\right)>0 \Leftrightarrow(1-\theta)(2 c-\varepsilon)+2\left(\theta a_{h}-a_{l}\right)<0$

$\Leftrightarrow(2 c-\varepsilon)-\theta(2 c-\varepsilon)+2 \theta a_{h}-2 a_{l}<0 \Leftrightarrow \theta<\frac{2\left(a_{l}-c\right)+\varepsilon}{2\left(a_{h}-c\right)+\varepsilon}<1$.

(iii) Since $E R_{p 2}^{*}-E R_{p 3}^{*}=-\frac{1}{4} \varepsilon\left[2 c(1-\theta)+\varepsilon \theta-2(1-\theta) a_{l}\right]>0$, it follows

when $2 c(1-\theta)+\varepsilon \theta-2(1-\theta) a_{l}<0 \Leftrightarrow 2 c-2 c \theta+\varepsilon \theta-2 a_{l}+2 \theta a_{l}<0$

$\Leftrightarrow \theta\left(2 a_{l}+\varepsilon-2 c\right)<2\left(a_{l}+c\right) \Leftrightarrow \theta<\frac{2\left(a_{l}-c\right)}{2\left(a_{l}-c\right)+\varepsilon}$.

\section{Appendix B Proof of Lemma 3}

Taking pairwise difference of $\theta_{1}, \theta_{2}$ and $\theta_{3}$, we have $\theta_{1}-\theta_{2} \geq 0, \theta_{1}-\theta_{3} \geq 0, \theta_{2}-\theta_{3} \geq 0$, where $a_{l}-c \leq \frac{\varepsilon^{2}}{2\left[\varepsilon-2\left(a_{h}-a_{l}\right)\right]}$. However, when $\varepsilon<2\left(a_{h}-a_{l}\right)$ and $a_{l}-c>\frac{\varepsilon^{2}}{2\left[\varepsilon-2\left(a_{h}-a_{l}\right)\right]}$, the inequality above is not binding. Thus, we get $\theta_{3}>\theta_{2}>\theta_{1}$.

\section{Appendix C Proof of Proposition 2}

(i) If $\varepsilon \geq 2\left(a_{h}-a_{l}\right)$, we get $\theta_{1} \geq 1$, leading to $E R_{p 1}^{*}-E R_{p 2}^{*}>0, \forall \theta$. By utilizing lemma 1 , we have $E R_{p 1}^{*}>E R_{p 3}^{*}$, where $\theta<\theta_{2}$; however, $E R_{p 1}^{*} \leq E R_{p 3}^{*}$, when $\theta \geq \theta_{2}$. 
(ii) If $\varepsilon<2\left(a_{h}-a_{l}\right)$, by invoking lemma 2, we get $\theta_{3}>\theta_{2}>\theta_{1}$; by using lemma 2, when $\theta \geq \theta_{3^{\prime}}$ the decision is to use $p 3$ strategy; when $\theta_{3}>\theta \geq \theta_{1}$, the decision is to use $p 2$ strategy; when $\theta<\theta_{1}$, the decision is $p 1$ strategy.

\section{Appendix D Comparison between the Pooling Equilibrium and the Separating Equilibrium} When $a_{l}<\varepsilon+c$

Proof Of Appendix D. By utilizing lemma 2, given $\varepsilon \geq 2 \Delta a$, if $\theta \geq \theta_{2}$, the best choice is to adopt $p 3$ strategy; if $\theta<\theta_{2}$, the decision is to adopt $p 1$ strategy. We can conclude that given $\varepsilon \geq 2 \Delta a$, if $\theta<\theta_{4^{\prime}}$ then $p 1>s 1$; if $\theta>\theta_{5}$, then $p 3>s 1$. Where $>$ denotes is preferred to.

Lemma A1. In the case that $\varepsilon>a_{l}-c>\frac{7}{9} \varepsilon$, it follows immediately that $\theta_{2}>\theta_{4}$ and $\theta_{2}<\theta_{5}$; however, when $\frac{7}{9} \varepsilon \geq a_{l}-c$, it leads to $\theta_{2} \leq \theta_{4}$ and $\theta_{2} \geq \theta_{5}$.

With lemma A1, we conclude that given $\varepsilon>a_{l}-c>\frac{7}{9} \varepsilon$ when $\theta<\theta_{4^{\prime}}$, the patentee's best choice is to pursue $p 1$ : a pooling equilibrium strategy. However, when $\theta_{4} \leq \theta \leq \theta_{5}$, the patentee's best choice is to pursue s1: a separating equilibrium strategy; Finally, when $\theta>\theta_{5}$, the patentee's best policy is to use $p 3$ : a pooling equilibrium. On the other hand, given $\frac{7}{9} \varepsilon \geq a_{l}-c$ with $\theta<\theta_{2}$, it is found $p 1>s 1$; when $\theta>\theta_{2}$, we have $p 3>s 1$. Therefore, $s 1$ will not be adopted, and the patentee's best policy will be to revert to the pooling equilibrium.

Finally, it is to be noted that from

$23 c^{2}+18 c \varepsilon-9 \varepsilon^{2}+a_{l}\left(23 a_{l}-18 \varepsilon-46 c\right)=\left[a_{l}-c-(3-4 \sqrt{2})\right]\left[a_{l}-c+(3+4 \sqrt{2})\right]>0$, we can derive that $\theta_{5}>0$.

\section{Appendix E Comparison between the Pooling Equilibrium and the Separating Equilibrium, When $a_{l} \geq \varepsilon+c$}

(1) Since $E R_{p 1}-E R_{s 2}=\frac{1}{4} \varepsilon\left[\varepsilon(1-\theta)-2 \theta\left(a_{h}-a_{l}\right)\right]>0, \theta<\theta_{6} \equiv \frac{\varepsilon}{\varepsilon+2\left(a_{h}-a_{l}\right)}$

(2) Since $E R_{p 2}-E R_{s 2}=-\frac{\varepsilon^{2} \theta}{4}<0$, we obtain $E R_{p 2}-E R_{s 2}<0, \forall \theta$.

(3) Since $E R_{p 3}-E R_{s 2}=-\frac{1}{4} \varepsilon(1-\theta)\left(a_{l}-c\right)<0$, we obtain $E R_{p 3}-E R_{s 2}<0, \forall \theta$.

\section{References}

1. Kamien, M.I.; Tauman, Y. The Private Value of Patent: A Game Theoretic Analysis. J. Econ. (Suppl.) 1984, 4, 93-118.

2. Arrow, K. Economic Welfare and the Allocation of Resources for Invention. In the Rate and Direction of Incentive Activity; Nelson, R.R., Ed.; Princeton University Press: Princeton, NJ, USA, 1962.

3. Fudenberg, D.; Tirole, J. Game Theory; The MIT Press: Cambridge, MA, USA, 1993.

4. Gallini, N.; Winter, R. Licensing in the Theory of Innovation. RAND J. Econ. 1985, 16, 237-252. [CrossRef]

5. Katz, M.; Shapiro, C. On the Licensing of Innovations. RAND J. Econ. 1985, 16, 504-520. [CrossRef]

6. Katz, M.; Shapiro, C. How to License Intangible Property. Q. J. Econ. 1986, 101, 567-589. [CrossRef]

7. Kamien, M.I.; Schwartz, N. Market Structure and Innovation; Cambridge University Press: Cambridge, MA, USA, 1982.

8. Kamien, M.I.; Tauman, Y. Fees versus Royalties and the Private Value of a Patent. Q. J. Econ. 1986, 101, 471-491. [CrossRef]

9. Muto, S. On Licensing Policy in Bertrand Competition. Game Econ. Behav. 1993, 5, 257-267. [CrossRef]

10. Lee, J.Y.; Huang, C.S. Vertical-Differentiation and Licensing Strategies. Ind. Econ. Res. 2006, 4, 1-10. (In Chinese)

11. Poddar, S.; Sinha, U.B. Patent Licensing from a High-cost Firm to a Low-cost Firm. Econ. Rec. 2010, 86, 384-395. [CrossRef]

12. Kabiraj, T.J. Fee vs. Royalty Licensing and Consumers' Welfare. J. Quant. Econ. 2017. [CrossRef] 
13. Kim, S.L.; Lee, S.H.; Matsumura, T. Eco-technology licensing by a foreign innovator and privatization policy in a polluting mixed duopoly. J. Asia-Pac. J. Account. Econ. 2017, 25, 433-448. [CrossRef]

14. Zhang, H.; Wang, X.; Hong, X.; Lu, Q. Technology Licensing in a Network Product Market: Fixed-Fee versus Royalty Licensing. Econ. Rec. 2018, 94, 168-185. [CrossRef]

15. Xu, H.; Tan, D. Optimal Abatement Technology Licensing in a Dynamic Transboundary Pollution Game: Fixed Fee Versus Royalty. Comput. Econ. 2019, 1-13. [CrossRef]

16. Wang, X.H. Fee versus Royalty Licensing in a Cournot Duopoly Model. Econ. Lett. 1998, 60, 55-62. [CrossRef]

17. Wang, X.H. Fee versus Royalty Licensing in a Differentiated Cournot Duopoly. J. Econ. Bus. 2002, 54, $253-266$. [CrossRef]

18. Chen, Y.W.; Yang, Y.P.; Wang, F.S.; Wu, S.J. Technology Licensing in Mixed Oligopoly. Int. Rev. Econ. Financ. 2014, 31, 193-204. [CrossRef]

19. Taylor, C.T.; Silberston, Z.A. The Economic Impact of the Patent System: A Study of the British Experience; Cambridge University Press: Cambridge, MA, USA, 1973.

20. Rostoker, M. A Survey of Corporate Licensing. Idea 1984, 24, 59-92.

21. Stamatopoulos, G.; Tauman, T. On the Superiority of Fixed Fee over Auction in Asymmetric Markets. Games Econ. Behav. 2009, 67, 331-333. [CrossRef]

22. Kishimoto, S.; Watanabe, N.; Muto, S. Bargaining Outcomes in Patent Licensing: Asymptotic Results in a General Cournot Market. Math. Soc. Sci. 2011, 61, 114-123. [CrossRef]

23. Miao, C.H. On the Superiority of Fixed Fee over Auction in Technology Licensing. Manch. Sch. 2013, 81, 324-331. [CrossRef]

24. Heywood, J.S.; Li, J.; Ye, G. Per Unit vs. Ad Valorem Royalties under Asymmetric Information. Int. J. Ind. Organ. 2014, 37, 38-46. [CrossRef]

25. Jeon, D.S.; Lefouili, Y. Cross-licensing and Competition. Rand J. Econ. 2018, 49, 656-671. [CrossRef]

26. Lee, J.H.; Kim, E.; Sung, T.-E.; Shin, K. Factors Affecting Pricing in Patent Licensing Contracts in the Biopharmaceutical Industry. Sustainability 2018, 10, 3143. [CrossRef]

27. Lee, J.H.; Sung, T.-E.; Kim, E.; Shin, K. Evaluating Determinant Priority of License Fee in Biotech Industry. J. Open Innov. Technol. Mark. Complex. 2018, 4, 30. [CrossRef]

28. Beggs, A.W. The licensing of patents under asymmetric information. Int. J. Ind. Organ. 1992, 10, $171-191$. [CrossRef]

29. Sen, D. On the Coexistence of Different Licensing Schemes. Int. Rev. Econ. Financ. 2005, 14, $393-413$. [CrossRef]

30. Fan, C.; Jun, B.H.; Wolfstetter, E.G. Optimal licensing under incomplete information: The case of the inside patent holder. Econ. Theory 2017. [CrossRef]

31. Shy, O. Industrial Organization; The MIT Press: Cambridge, MA, USA, 1995.

32. Tirole, J. The Theory of Industrial Organization; The MIT Press: Cambridge, MA, USA, 1988. 